\title{
Nanobody-Directed Specific Degradation of Proteins by the 26S-Proteasome in Plants
}

\author{
Bianca Baudisch, Ingrid Pfort, Eberhard Sorge and Udo Conrad* \\ Phytoantibody Group, Department of Molecular Genetics, Leibniz Institute of Plant Genetics and Crop Plant Research, \\ Gatersleben, Germany
}

Here, we present data showing the directed degradation of target proteins recognized by a specific nanobody in transgenic plants. Green fluorescent protein was depleted by a chimeric nanobody fused to a distinct F-box domain, which enables protein degradation via the ubiquitin proteasome pathway. This technique could thus be used to knock out other proteins of interest in planta using specific, high-affinity binding proteins.

Keywords: protein degradation, GFP, transgenic plants, proteasome, deGradFP

\section{OPEN ACCESS}

Edited by:

Liwen Jiang,

The Chinese University of Hong Kong,

Hong Kong

Reviewed by:

Jean-Marc Neuhaus,

University of Neuchâtel, Switzerland

Yule Liu,

Tsinghua University, China

${ }^{*}$ Correspondence:

Udo Conrad

conradu@IPK-gatersleben.de

Specialty section:

This article was submitted to

Plant Cell Biology,

a section of the journal

Frontiers in Plant Science

Received: 19 September 2017

Accepted: 23 January 2018

Published: 09 February 2018

Citation:

Baudisch B, Pfort I, Sorge E and Conrad U (2018) Nanobody-Directed Specific Degradation of Proteins by the 26S-Proteasome in Plants.

Front. Plant Sci. 9:130

doi: 10.3389/fpls.2018.00130

\section{INTRODUCTION}

Modern cell biology approaches require an understanding of biomolecular pathways and extensive knowledge of protein-protein interactions as a basis of regulatory networks. The manipulation of regulatory and coding sequences by classical mutagenesis, by CRISPR/Cas9 knockout (Bortesi and Fischer, 2015) or by targeting specific transcripts with RNAi, is widely used for analyzing protein function in detail. Whereas genome-wide comparative analysis of transcript and protein levels in Arabidopsis suggests that regulation primarily occurs at the transcript level, in many cases, transcript abundances do not necessarily reflect the abundances of the corresponding proteins (Baerenfaller et al., 2008). Direct influence at the protein level could be a more effective way to study protein functions in plants in vivo. Immunomodulation of regulatory compounds by the expression of specific recombinant antibodies has been developed as a tool to directly affect the function of desired targets in plant cells. The blockage or change of phytohormone functions via plantibodies by building artificial sinks (Artsaenko et al., 1995) or by direct interaction (ten Hoopen et al., 2007) has been reported in several papers (Conrad and Manteuffel, 2001). Functional plant protein (Miroshnichenko et al., 2005) and plant viral protein (Tavladoraki et al., 1993; Boonrod et al., 2004) blockage by in planta expression of recombinant antibodies has also been described. The selection of antibodies that specifically inhibit protein functions could be a rather difficult task. The specific intracellular degradation of functional proteins would be a useful solution to this problem. In animal and yeast cells, the ubiquitin-proteolytic apparatus (Ravid and Hochstrasser, 2008) has been manipulated by altering the substrate recognition domain of ubiquitin-protein ligases. Chimeric substrate receptors or peptide-small molecule hybrids could cause the intended target to interact with the substrate receptor of the E3-ligases to allow for the directed degradation of selected proteins (Zhou et al., 2000; Sakamoto et al., 2001; Zhou, 2005). In a similar approach, researchers have adapted an auxin-dependent protein degradation pathway that enables plants to degrade auxin transcription repressors (AUX/IAA) by a specific

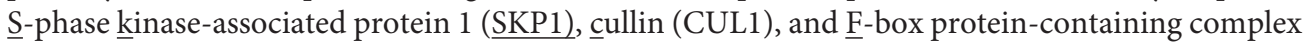
(SCF)-ubiquitin E3-ligase complex. This system allows for a rapid and inducible depletion of target proteins in a reversible and tunable manner by the phytohormone auxin in budding yeast 
and several animal cells, including human cells, but not in plant cells (Nishimura et al., 2009). New regulation principles introduced by this technology fit into synthetic biology approaches. Caussinus et al. (2011) developed a method for specific protein degradation by replacing the target recognition sequence of the F-box protein by a target-specific nanobody in Drosophila and human cells. The degradation of nuclear proteins fused to green fluorescent protein (GFP) using anti-GFP nanobody-targeted E3-ubiquitin ligase complexes in mammalian cells and zebrafish embryos has also been shown (Ju Shin et al., 2015). Nanobodies are stable, small, single-domain antibodies that can be selected by phage display (Muyldermans, 2013). In principle, a ubiquitous approach is possible because specific nanobodies for virtually any protein can be selected with this method. Off-target effects could be avoided by performing extensive selection and characterization of nanobodies with specific binding parameters. To specifically degrade GFP, we expressed the fusion protein NSlmb-VHHGFP4 in the cytosol of transgenic plant cells that showed overexpression of GFP (Figure 1). Experimental analysis of the leaf material showed evidence of GFP depletion. With this experiment, we show for the first time that nanobody-driven directed degradation of proteins can also be used in plants. This allows for a plethora of experiments to analyze the role of single regulatory proteins and adds an important component to an integrated synthetic biology concept for plants.

\section{MATERIALS AND METHODS}

\section{Construction of Expression Vectors}

Cloning was performed as previously described (Sambrook, 2001). DreamTaq polymerase, FastDigest restriction enzymes, and T4 DNA ligase from Thermo Fisher Scientific were used according to the manufacturer's instructions.

\section{Construction of the GFP Plant Expression Vector}

A XbaI/XhoI fragment containing the CaMV-enhanced 35S promoter (d35S) was released from plasmid d35S-Nos-AB-M (Himmelbach et al., 2007) and inserted in the pGFP-Amp vector to form pGH102. The SfiI fragment of vector pGH102 harboring the full GFP expression cassette was introduced into the appropriate sites of plasmid p6d35S (Hensel et al., 2015) to generate the vector $\mathrm{pGH} 219$.

\section{Construction of NSImb-VHHGFP4 and NSnoFbox-VHHGFP4 Plant Expression Vectors}

Template sequences (NSImb-VHHGFP4 and NSnoFboxVHHGFP4) were provided by Caussinus et al. (2011). NSlmb-VHHGFP4 comprises the sequence encoding the F-box domain containing in the $\underline{N}$-terminal part of the F-box protein supernumerary limbs (Slmb) from Drosophila melanogaster fused to the GFP-binding nanobody VHHGFP4 sequence. NSnoFbox-VHHGFP4 lacks the F-box domain for SKP1 binding and represents the negative control used in later GFP-depletion assays. The primer pair Slmb-NcoI-for and Slmb-NotI-rev was used to add NcoI and NotI sites by PCR. The resulting fragments were subcloned using the TOPO Cloning Kit (Thermo Fisher Scientific). After the plasmids were sequenced and cut with NcoI and NotI, the fragment was inserted into the pRTRA vector. The resulting expression cassette was cut using HindIII and ligated into the binary vector pCB301-Kan. The resulting plasmids (containing the NSImb-VHH-GFP4 or NSnoFbox-VHHGFP4 constructs) were used for transformation of Agrobacterium tumefaciens strain GV2260.

\section{Production of Transgenic Plants}

Transformation of Nicotiana tabacum was performed by agroinfection of leaf discs (Horsch, 1985) as described by Floss et al. (2010). The leaf discs were submerged for $1 \mathrm{~h}$ in an A. tumefaciens culture, plated on MS medium, and stored at $24^{\circ} \mathrm{C}$ in the dark for 2 days. Then, the explants were transferred to NBKC medium (MS medium containing $0.2 \mathrm{mg} / \mathrm{L}$ $\alpha$-naphthaleneacetic acid, $1 \mathrm{mg} / \mathrm{L}$ 6-benzylaminopurine, $50 \mathrm{mg} / \mathrm{L}$ kanamycin, and $500 \mathrm{mg} / \mathrm{L}$ cefotaxime). Every 10-14 days, the plant material was removed and placed in fresh NBKC medium until plantlets appeared. Plantlets $(2-3 \mathrm{~cm}$ in height) were placed onto MS medium containing $50 \mathrm{mg} / \mathrm{L}$ kanamycin for selection. Surviving putative transgenic plants were planted in soil and grown to maturity in a greenhouse.

\section{SDS-PAGE and Western Blotting}

Leaf discs were stored at $-80^{\circ} \mathrm{C}$, transferred to $2 \mathrm{~mL}$ safe-lock tubes along with two metal bullets, and disintegrated in a Retsch mill at a frequency of 28/s for 2 min under liquid nitrogen. Then, $150 \mu \mathrm{L}$ of $2 \times$ SDS sample buffer (Conrad et al., 1998) was added and heated at $95^{\circ} \mathrm{C}$ for $10 \mathrm{~min}$. Samples were then cooled on ice and centrifuged for $30 \mathrm{~min}$ at 21,000 $\times$ g. Extracted plant proteins (corresponding to $40 \mu \mathrm{g}$ protein) were separated by reducing SDS-PAGE (12\% polyacrylamide) and then electrotransferred to nitrocellulose membranes. The Western blotting procedure was carried out using monoclonal anti-cmyc antibodies following the protocol described by Gahrtz and Conrad (2009). The secondary antibody was sheep anti-mouse IgG horseradishperoxidase-linked whole antibody (GE Healthcare UK Ltd., Little Chalfont, Buckinghamshire, United Kingdom), and ECL was used for detection. GFP was detected with specific rabbit antiGFP antibodies and goat anti-rabbit IgG horseradish-peroxidaselinked whole antibody. Specific signals were detected as described above.

\section{Native Extraction of GFP from Tobacco Leaves}

Around $100 \mathrm{mg}$ of tobacco leaves was transferred to $2 \mathrm{~mL}$ safelock tubes along with two metal bullets and disintegrated in a Retsch mill at a frequency of $28 / \mathrm{s}$ for $2 \mathrm{~min}$ under liquid nitrogen. Then, $300 \mu \mathrm{L}$ of extraction buffer [ $50 \mathrm{mM}$ Tris, $\mathrm{pH} 8.0$, $5 \mathrm{mM}$ EDTA, $1 \mathrm{mM}$ DDT, $1 \times$ Complete proteinase inhibitor mix (Roche, Mannheim, Germany)] was added and the extracts were shaken end-over-end for $45 \mathrm{~min}$ at $4^{\circ} \mathrm{C}$. To analyze the stability 


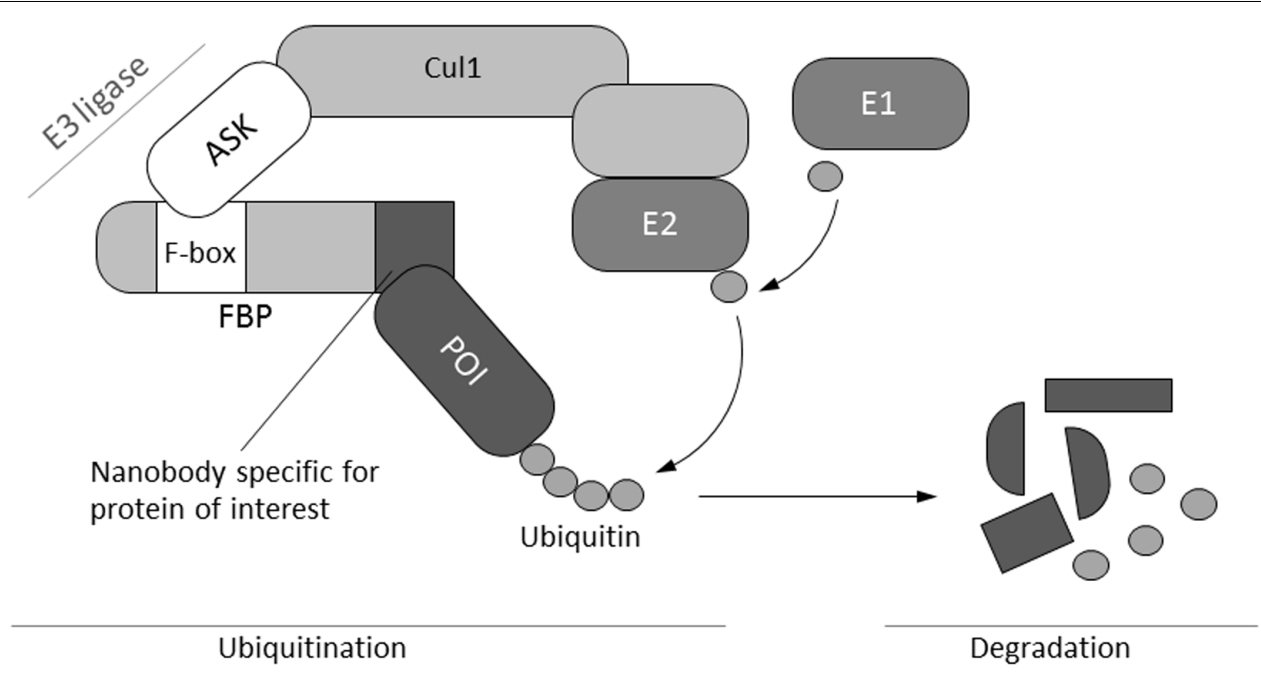

FIGURE 1 | Schematic illustration of the mechanism of selective protein degradation. Protein degradation by the ubiquitin pathway is carried out by a complex cascade of enzymes (E1-E3) that catalyze the covalent attachment of multiple ubiquitin molecules to the target protein. Subsequently, polyubiquitinated proteins are degraded by the proteasome. The N-terminal F-box domain typically binds to one of the members of the ASK family, whereas the C-terminal part determines substrate specificity via different protein-protein interaction motifs. These motifs are replaced by a nanobody specific for a protein of interest in order to engineer a molecular tool for selective protein depletion (Caussinus et al., 2011). Cul1, cullin; FBP, F-box protein; ASK, Arabidopsis-S-phase kinase-associated protein (SKP1)-like; E1, ubiquitin activating enzyme; E2, ubiquitin conjugating enzyme; E3-ligase, ubiquitin ligase; POI, protein of interest.

in solution, $50 \mu \mathrm{M}$ MG-132 (Sigma, Steinheim, Germany) was applied.

\section{Competitive ELISA to Measure GFP}

Enhanced green fluorescent protein (kindly provided by Mario Jakob, Universität Halle/Saale, Germany) was diluted in Phage PBS (100 mM NaCl, $32 \mathrm{mM} \mathrm{Na} \mathrm{HPO}_{4}$, $17 \mathrm{mM} \mathrm{NaH} \mathrm{PO}_{4}, \mathrm{pH}$ 7.2) at a concentration of $0.05 \mu \mathrm{g} / 100 \mu \mathrm{L}$ and put into Immunoplate MaxiSorp wells (Nalge Nunc International, Roskilde, Denmark). After overnight incubation at room temperature, the wells were saturated with $3 \%$ bovine serum albumin (BSA) in phosphate buffered saline, 0.05\% Tween 20 (PBS-T) (Gahrtz and Conrad, 2009). Standards (0.01-100 nM eGFP) and appropriately diluted native extracts were mixed with rabbit anti-GFP antibodies (diluted 1:50,000 in 3\% BSA-PBS-T) and incubated at $25^{\circ} \mathrm{C}$ for $30 \mathrm{~min}$ in a master plate. Samples were then transferred to the saturated eGFP plates and incubated for $1 \mathrm{~h}$ at $25^{\circ} \mathrm{C}$. After extensive washing with PBS-T, goat anti-rabbit IgG alkaline-phosphatase-linked whole antibody (Sigma, Steinheim, Germany), diluted 1:2000 in 3\% BSA and PBS-T, was applied for $1 \mathrm{~h}$ at $25^{\circ} \mathrm{C}$. After further washing the enzymatic substrate, $p$-nitrophenyl phosphate (pNPP) in $0.1 \mathrm{M}$ diethanolamine- $\mathrm{HCl}(\mathrm{pH} 9.8)$ was added, and the absorbance signal was measured at $405 \mathrm{~nm}$ after $1 \mathrm{~h}$ incubation at $37^{\circ} \mathrm{C}$. Measured values from control experiments performed in parallel (same handling procedure but without the antigen incubation step) were subtracted.

\section{Detection of Gene Expression by RT-PCR}

The OneTaq One-Step RT-PCR Kit (New England Biolabs) was used to identify GFP and actin mRNA. Analysis was performed according to the manufacturer's instructions. Briefly, total RNA from plant tissue was extracted using the RNeasy Plant Kit (Qiagen). For cDNA synthesis the following solutions were mixed and denatured at $70^{\circ} \mathrm{C}$ for $5 \mathrm{~min}$ : $10 \mu \mathrm{L}$ precipitated RNA $(1 \mu \mathrm{g})$, $9 \mu \mathrm{L}$ of $\mathrm{H}_{2} \mathrm{O}, 2 \mu \mathrm{L}$ of $10 \mu \mathrm{M}$ GFP reverse primer or $2 \mu \mathrm{L}$ of $10 \mu \mathrm{M}$ actin reverse primer, and $25 \mu \mathrm{L}$ of OneTaq OneStep Quick-Load Reaction Mix. Then, $2 \mu \mathrm{L}$ of $10 \mu \mathrm{M}$ GFP forward primer or $10 \mu \mathrm{M}$ actin forward primer and $1.8 \mu \mathrm{L}$ of OneTaq One-Step Enzyme Mix were added. PCR amplification was performed according to the following protocol for 40 cycles: $48^{\circ} \mathrm{C} 15 \mathrm{~min}, 94^{\circ} \mathrm{C} 1 \mathrm{~min}, 94^{\circ} \mathrm{C} 15 \mathrm{~s}, 63^{\circ} \mathrm{C} 30 \mathrm{~s}, 58^{\circ} \mathrm{C} 1 \mathrm{~min}$, and $68^{\circ} \mathrm{C} 5 \mathrm{~min}$. The resulting DNA fragments were separated on a $2 \%$ agarose gel in tris-acetate-EDTA, pH 8.0 (TAE) buffer (Sambrook, 2001).

\section{Primer Sequences}

ASK9/10-BamHI-for 5'-ATGGATCCTCGACGAAGAAGATC ATA-3'

ASK9-XhoI-rev $\quad 5^{\prime}$-TTCTCGAGTTCAAAAGCCCATTTATT

CTC-3'

ASK10-Xhol-rev $\quad 5^{\prime}$-TTCTCGAGTTCAAAACCCCATTGAT

TCT-3'

Slmb-NcoI-for3 5'-CCATGGCCATGATGAAAATGGAGACT GA-3'

Slmb-NotI-rev5 5'-TTGCGGCCGCGCTGGAGACGGTGAC CTG-3'

Slmb-BamHI-for3 5'-GCGGATCCATGATGAAAATGGAGA CTGAC-3'

Slmb-NotI-rev5 5'-TTGCGGCCGCGCTGGAGACGGTGA CCTG-3'

Slmb-NdeI-for3 5'-CATATGATGATGAAAATGGAGACTG ACAAAAT 


\author{
AATGGACGAAACCAACTCCAATGCACAGGCC- $3^{\prime}$ \\ Slmb-cmyc-NotI-rev5 5'-GCGGCCGCATTCAGATCCTCTT \\ CTGAGATGAG \\ TTTTTGTTCGTCGACGCTGGAGACGGTGACCTG-3' \\ VHHGFP4-NdeI-for 5'-GCATATGGATCAAGTCCAACTG \\ GTGGAGT-3' \\ VHHGFP4-SalI-rev $\quad 5^{\prime}$-GTCGACGCTGGAGACGGTGAC \\ CTG-3' \\ BamHI-VHHGFP4-for 5'-GGATCCATGGATCAAGTCCAA \\ CTGGTG-3' \\ NotI-VHHGFP4-rev 5'-GCGGCCGCGCTGGAGACGG \\ TGA-3' \\ Actin forward $5^{\prime}$-CTATTCTCCGCTTTGGACTTGGCA-3' \\ Actin reversed 5'-AGGACCTCAGGACAACGGAAACG-3' \\ GFP forward 5'-ATGGTGAGCAAGGGCGAGGAGCT-3'

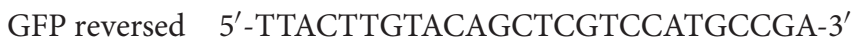

\section{RESULTS}

\section{Design of Expression Vectors and Production of Transgenic Plants Expressing NSImb-VHHGFP4, NSnoFbox-VHHGFP4, and GFP}

We constructed expression vectors allowing for the ubiquitous expression of either an NSlmb-VHHGFP4 (anti-GFP nanobody) or an NSnoFbox-VHHGFP4 fusion protein in the cytosol of plant cells. The CaMV35S promoter induces expression in nearly all plant cells, and the cmyc Tag enables detection of the fusion proteins by Western blot analysis (Figure 2). All expression cassettes were cloned into a binary plant expression vector allowing for the selection of transgenic plants via kanamycin resistance $\left(\mathrm{Km}^{R}\right)$. The second construct served as an internal control to show that the degradation of GFP was F-box domain dependent. We decided to use an animal-derived F-box variant and not a plant F-box variant to minimize the effects on general regulatory processes in plants. After leaf-disc transformation experiments were completed, 51 kanamycin-resistant plants transformed with NSlmb-VHHGFP4 were selected, grown, and analyzed by Western blot. Twenty lines with transgenic protein accumulation were detected. In addition, 51 kanamycin-resistant plants transformed with NSlmb-VHHGFP4 were selected, grown, and analyzed by Western blot. Seven lines with transgenic protein accumulation were detected. A binary plant expression vector (pGH219) allowing for the ubiquitous cytosolic expression of GFP, also driven by the CaMV35S promoter, was used for super-transformation of NSlmb-VHHGFP4 and NSnoFboxVHHGFP4 lines. This vector allows for the selection of hygromycin-resistant transgenic plants (Figure 2). Wild-type $N$. tabacum (tobacco) plants were transformed as controls and GFP expression was detected by rabbit anti-GFP antibodies (Figure 3).

\section{Directed Degradation of GFP in Transgenic Tobacco Plants}

Four independent lines expressing the NSlmb-VHHGFP4 fusion protein and two independent lines expressing the NSnoFboxVHHGFP4 fusion protein were super-transformed with a transgene encoding GFP as a reporter for protein degradation. Overall, 11 kanamycin- and hygromycin-resistant tobacco lines deriving from different super-transformation experiments were selected that showed NSlmb-VHHGFP4 accumulation, but little to no GFP accumulation was observed by Western blot analysis using highly specific rabbit anti-GFP antibodies (Figure 3 and Table 1). Conversely, strong GFP accumulation was detected in transgenic plants expressing NSnoFbox-VHHGFP4. Six kanamycin/hygromycin lines (derived from two NSnoFboxVHHGFP4 fusion protein expressing lines) were analyzed that showed NSnoFbox-VHHGFP4 fusion protein expression and GFP expression. The results of the analysis of two NSnoFboxVHHGFP4-GFP lines are demonstrated in Figure 3. To
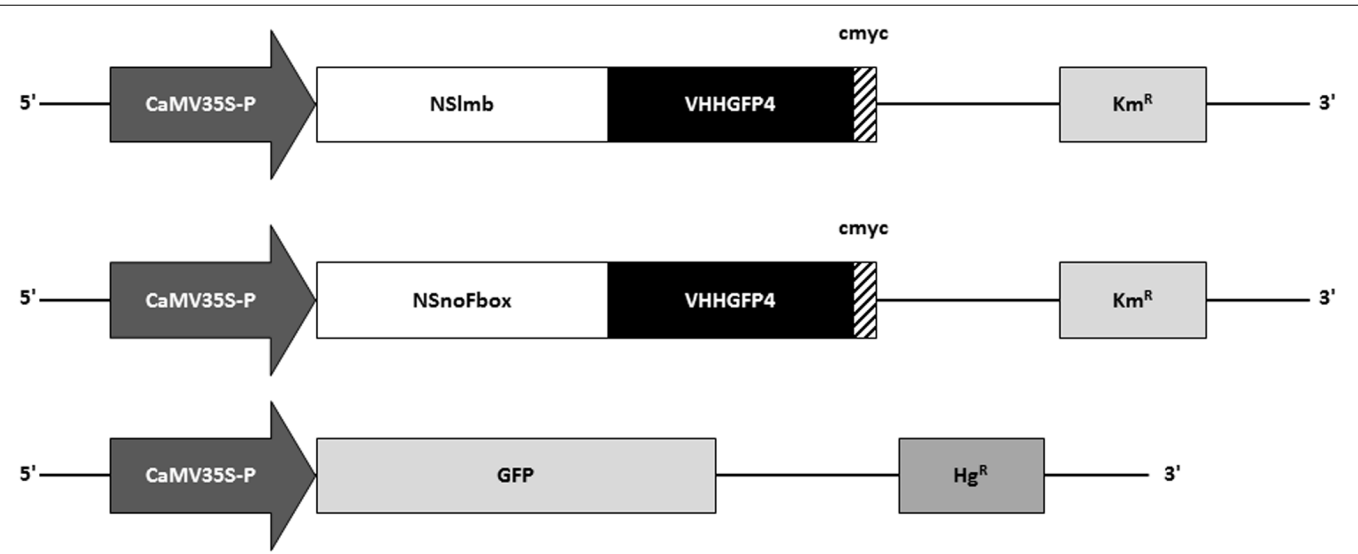

FIGURE 2 | Schematic depiction of constructs used for expression of NSImb-VHHGFP4, NSnoFbox-VHH, and GFP in transgenic tobacco plants. NSImb-VHHGFP4

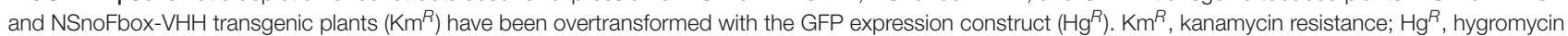
resistance; CaMV35S-P, CaMV35S ubiquitous promoter; NSImb, F-box protein from Drosophila (Caussinus et al., 2011); NSnoFbox, NSImb with deleted F-box domain (Caussinus et al., 2011); GFP, green fluorescent protein; VHH, nanobody; cmyc, cmyc polypeptide protein tag. 

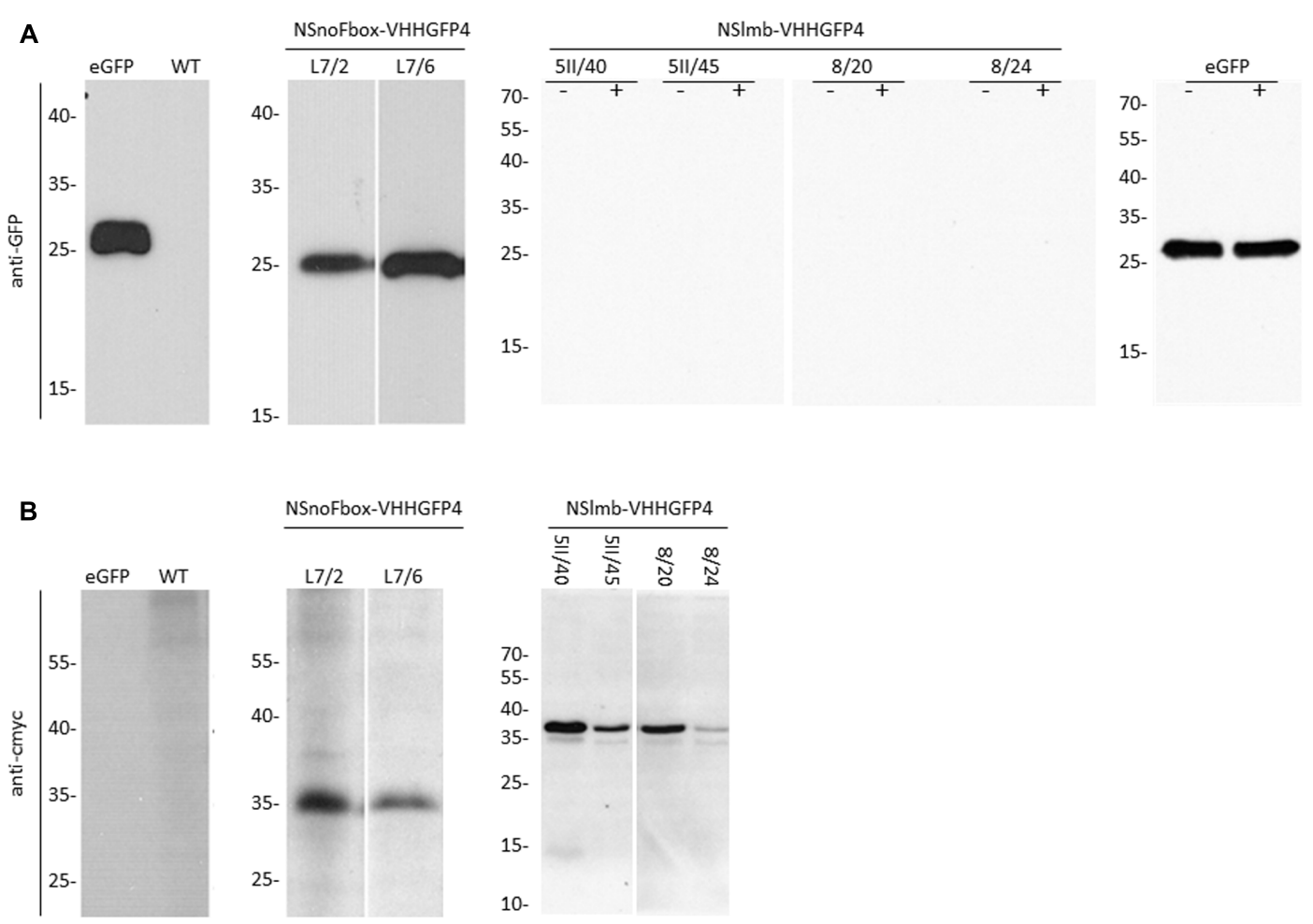

FIGURE 3 | Protein expression analysis (Western blot) with anti-GFP antibodies, anti-rabbit peroxidase, and ECL (A) and anti-cmyc antibodies, anti-mouse peroxidase, and ECL (B), of transgenic lines expressing NSImb-VHHGFP4 and GFP (5II/40, 5II/45, 8/20, 8/24), NSnoFbox-VHHGFP4 and GFP (L7/2, L7/6), and GFP (GFP) and of tobacco wild-type (WT) plants. NSnoFbox-VHHGFP4 (fusion protein with deleted F-box domain) and WT plants served as controls. The size of molecular marker proteins is given in kilodalton. The expected molecular weights of GFP, NSImb-VHHGFP4, and NSnoFbox-VHHGFP4 are 27, 39 , and 35 kDa, respectively. Extracts of $5 \mathrm{Il} / 40,5 \mathrm{II} / 45,8 / 20,8 / 24$, and GFP have been treated with MG-132 (+) or not (-). In both cases GFP protein expression is lacking in $5 \mathrm{Il} / 40$, 5II/45, 8/20, and 8/24. eGFP, pure eGFP.

strengthen these results quantitatively, GFP accumulation was measured by a competitive ELISA, which could detect GFP concentrations between 4 and $0.1 \mathrm{nM}$ (Figure 4). In all nine F-box transgenic plants investigated by the competitive ELISA, GFP concentrations were determined to be below $0.1 \mathrm{nM}$ (detection limit, Figure 4 and Table 1). GFP concentration was significantly higher in NSnoFbox-VHHGFP4-GFP lines and in GFP expressing tobacco plants (Figure 4). In further experiments, we wanted to rule out that the lack of GFP protein expression was due to loss of the transgene or to downregulation at the transcriptional level. Using reverse transcription and PCR amplification with specific primers, we showed that NSlmbVHHGFP4 plants contained GFP transcripts in similar amounts to NSnoFbox-VHHGFP4 plants (Figure 5). The detection of transcripts indicates the presence of the transgene coding for GFP. Consequently, the lack of GFP accumulation in NSlmbVHHGFP4 plants detectable via Western blot analysis is not due to downregulation at the transcriptional level. To rule out, that the removal of GFP by directed proteolysis did occur after extraction, we added MG132, a potent inhibitor of the proteasome (Lee and Goldberg, 1998) to the extraction buffer. The samples, that have been either treated with MG132 or not, show identical bands for the NSlmb-VHHGFP4 plants, the NSnoFbox-VHHGFP4 plants, and the GFP plants, as
TABLE 1 | Summary of anti-GFPVHH F-box fusion protein accumulation measured by anti-cmyc Western blot, GFP protein accumulation measured by anti-GFP Western blot, and competitive ELISA and GFP transcript expression detected by reverse transcription and PCR.

\begin{tabular}{lcccc}
\hline No. & $\begin{array}{c}\text { Anti-cmyc } \\
\text { Western }\end{array}$ & $\begin{array}{c}\text { Anti-GFP } \\
\text { Western }\end{array}$ & $\begin{array}{c}\text { Anti-GFP } \\
\text { ELISA }\end{array}$ & $\begin{array}{c}\text { GFP } \\
\text { transcript }\end{array}$ \\
\hline $5 \mathrm{l} / 5$ & + & - & Not done & + \\
$5 \mathrm{I} / 88$ & + & - & Not done & + \\
$5 \mathrm{II} / 21$ & + & $-(+)$ & $<0.1 \mathrm{nM}$ & + \\
$5 \mathrm{II} / 22$ & + & - & $<0.1 \mathrm{nM}$ & + \\
$5 \mathrm{II} / 24$ & + & $-(+)$ & $<0.1 \mathrm{nM}$ & + \\
$5 \mathrm{II} / 31$ & + & $-(+)$ & $<0.1 \mathrm{nM}$ & + \\
$5 \mathrm{II} / 40$ & + & - & $<0.1 \mathrm{nM}$ & + \\
$5 \mathrm{II} / 45$ & + & - & $<0.1 \mathrm{nM}$ & + \\
$8 / 15$ & + & - & $<0.1 \mathrm{nM}$ & + \\
$8 / 20$ & + & - & $<0.1 \mathrm{nM}$ & + \\
$8 / 24$ & + & $<0.1 \mathrm{nM}$ & + \\
\hline
\end{tabular}

well (Figure 3). These results clearly demonstrate that GFP is degraded at the protein level in the presence of the F-box domain in the plant cells, whereas the lack of the F-box domain leads to GFP accumulation (summarized in Table 1). 
A

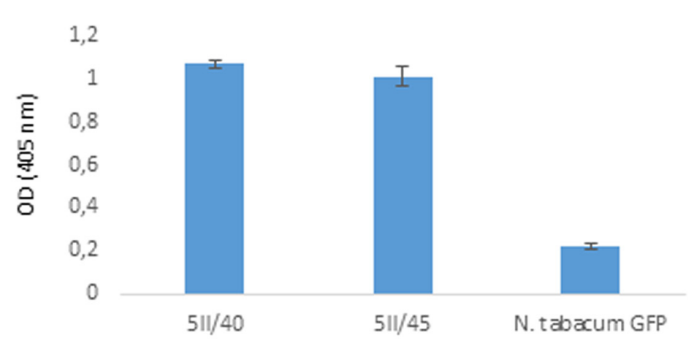

B

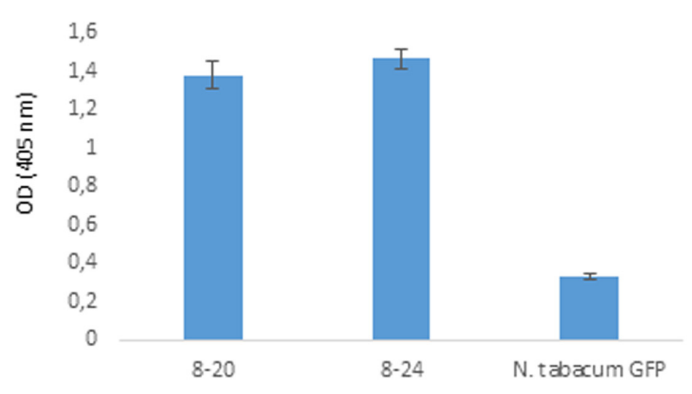

C

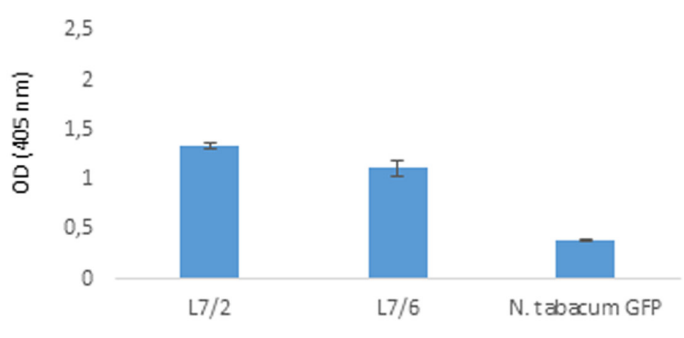

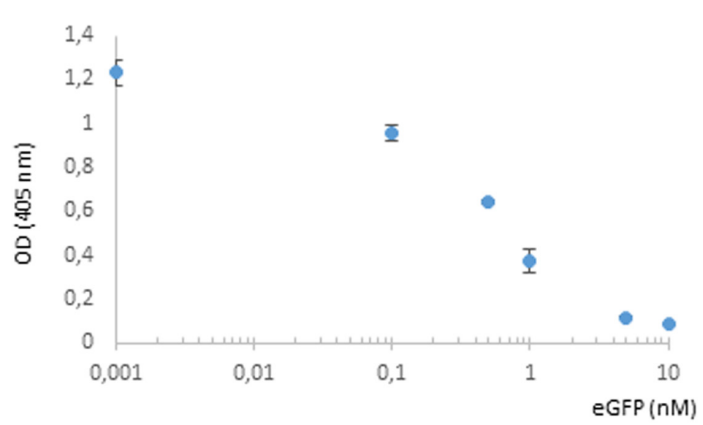
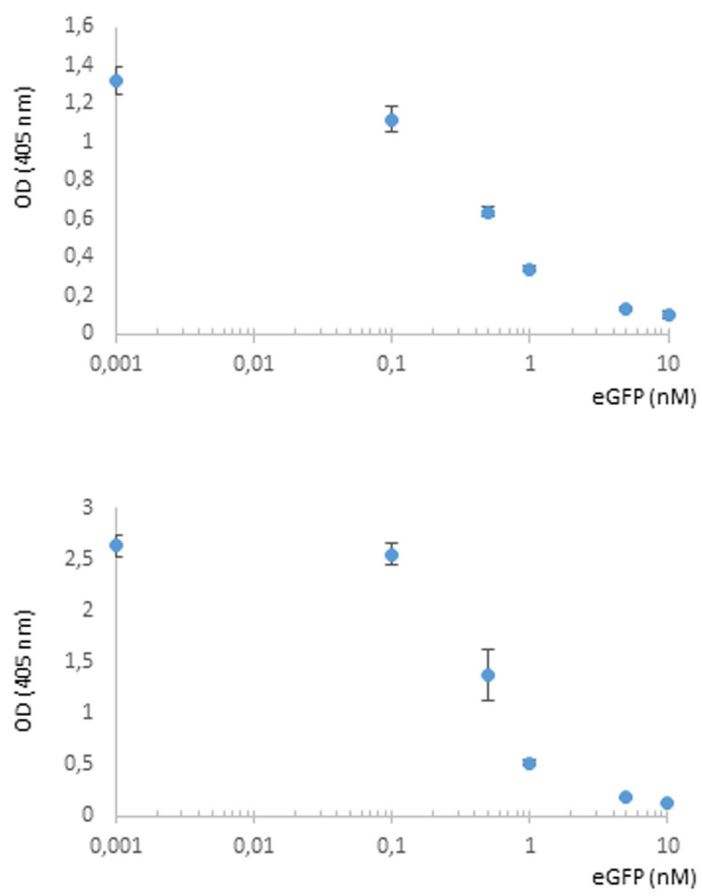

FIGURE 4 | Selective degradation of GFP driven by NSImb-VHHGFP4 fusion proteins in planta measured by competitive ELISA for quantification of GFP. Five parallels of each native plant extract dilution as well as five parallels of each eGFP standard dilution were incubated and measured on the same ELISA plate. GFP plant extracts (N. tabacum GFP) were also measured on each plate. Resulting arithmetic means were presented including standard deviations given as bars. (A,B) Transgenic lines expressing NSImb-VHHGFP4 and GFP. (C) Transgenic lines expressing NSnoFbox-VHHGFP4 and GFP.
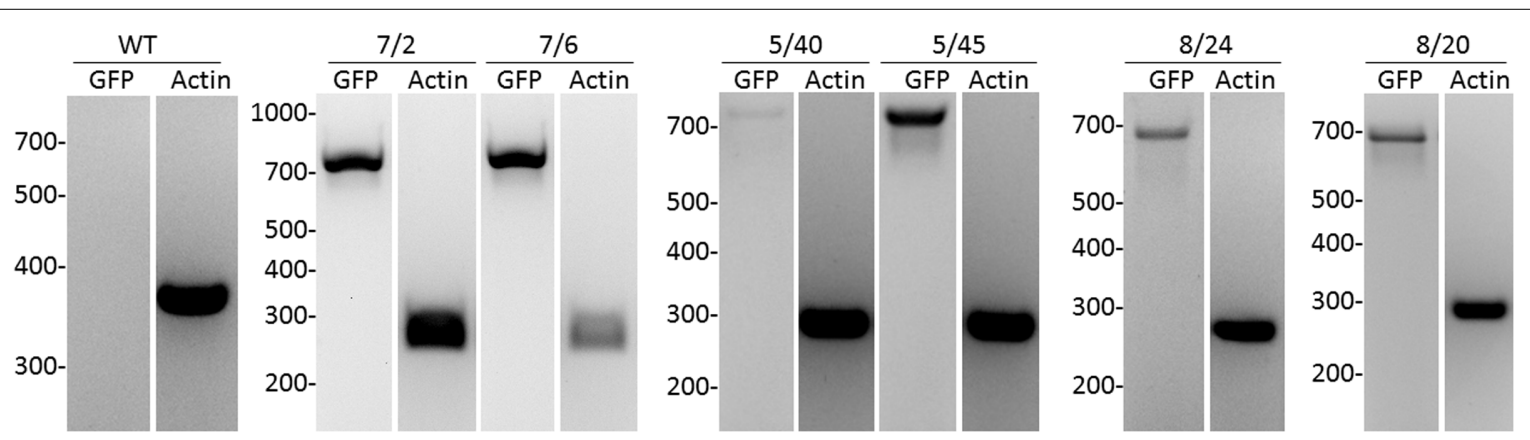

FIGURE 5 | Analysis of GFP transcripts in transgenic tobacco plants by reverse transcription and PCR compared to actin transcription. As internal standard, a housekeeping gene encoding for ribosomal protein actin9 in N. tabacum was analyzed (Volkov et al., 2003). NSImb-VHHGFP4 (8/20, 8/24, 5/40, 5/45), NSnoFbox-VHHGFP4 (L7/2, L7/6), and wild-type plant (WT) were analyzed. The expected length/size of the PCR products was 720 bp for GFP and 260 bp for actin. 


\section{Drosophila F-Box Domain Can Induce Selective Protein Degradation in Plant Cells}

The interaction of the F-box domain with plant SKP1 (Vierstra, 2009) is presumed to have caused the effect described above. SKP1-like proteins, called ASKs, have been described in plants (Zhao et al., 2003). The specific interaction between the F-box domain of Drosophila and SKP1-like proteins in plants that act as adaptors to link the F-box protein to the scaffold of the SCF complex (Figure 1) has been shown by in vitro ELISA interaction studies (see Supplementary Material). This result shows that the F-box domain from Drosophila is capable of recognizing the SKP1-analogous ASK proteins of plants.

\section{DISCUSSION}

The 26S proteasome, a ubiquitous machine in eukaryotes, could be used to manipulate protein functions in vivo. Manipulation, in this sense, means degradation of the functional protein of interest. This would aid in learning more about specific regulatory processes or designing new pathways in the context of new concepts in plant breeding and secondary metabolite engineering (Staniek et al., 2013). We show in the present paper that the degradation of solitary GFP molecules was possible in plants. This is a crucial first step toward directly targeting plant proteins and removing them to gain new insights into their functions. Interestingly, in Drosophila, the modified SCF E3-ligase could not process solitary GFP molecules, whereas GFP fusion proteins were degraded (Caussinus et al., 2011). A major benefit of this new technology is strong and selective degradation. Off-target effects could only be caused by nonspecific antibody binding. Here, several types of small, specific binders have recently been developed that all are selectable and allow specific and high-affinity binding. This includes single-chain Fv (scFv) (Bird et al., 1988) and nanobodies (Muyldermans, 2013), the most common forms of recombinant antibodies. The direct expression of scFv in the cytoplasm of target cells leads in only a few cases $(<1 \%)$ to sufficient stable intrabodies (Auf der Maur et al., 2004; Visintin et al., 2004). Binders with high-affinity constants could be enriched by mimicking affinity maturation in vitro with phage display (Chowdhury and Pastan, 1999). Nanobodies are beneficial in this context, because they have a low molecular weight and a

\section{REFERENCES}

Artsaenko, O., Peisker, M., zur Nieden, U., Fiedler, U., Weiler, E. W., Muntz, K., et al. (1995). Expression of a single-chain Fv antibody against abscisic acid creates a wilty phenotype in transgenic tobacco. Plant J. 8, 745-750. doi: 10. 1046/j.1365-313X.1995.08050745.x

Auf der Maur, A., Tissot, K., and Barberis, A. (2004). Antigen-independent selection of intracellular stable antibody frameworks. Methods 34, 215-224. doi: 10.1016/j.ymeth.2004.04.004

Baerenfaller, K., Grossmann, J., Grobei, M. A., Hull, R., Hirsch-Hoffmann, M., Yalovsky, S., et al. (2008). Genome-scale proteomics reveals Arabidopsis thaliana gene models and proteome dynamics. Science 320, 938-941. doi: 10. 1126/science. 1157956 stable immunoglobulin antigen binding unit and can recognize cryptic epitopes (Helma et al., 2015). Synthetic biology uses recombinant binders to control gene transcription, to change signaling cascades and to influence protein turnover (Lienert et al., 2014). In general, a central idea of the synthetic biology approach is the rational design of genetic building blocks. Novel cellular functions could be created and designed that target several new purposes and applications (Helma et al., 2015). In this paper, we show the targeted proteasomal knockdown of GFP by use of a specific anti-GFP nanobody in plants. Engineering of plants in terms of resistance development by removing pathogen effector proteins is one potential application of targeted protein degradation. This concept of selective protein degradation, now proven in principle, could also be used to manipulate regulatory pathways in plants. A plethora of experiments using selected degradation and selected activation of genes by specific nanobodies could be performed and lead to developing new strategies in crop plant design for agriculture in the future.

\section{AUTHOR CONTRIBUTIONS}

BB and UC planned and designed the research. BB, IP, and ES performed the experiments and analyzed the data. UC and ES wrote the manuscript.

\section{ACKNOWLEDGMENTS}

We thank Mario Jacob (Martin Luther University of HalleWittenberg) for the generous gift of overexpressed and purified eGFP; Marcel Quint (Martin Luther University of HalleWittenberg) for providing the clones for ASK9 and ASK10; and Christine Helmhold, Isolde Tillack, and Ulrike Gresch (Leibniz Institute of Plant Genetics and Crop Plant Research) for their excellent technical assistance.

\section{SUPPLEMENTARY MATERIAL}

The Supplementary Material for this article can be found online at: https://www.frontiersin.org/articles/10.3389/fpls.2018.00130/ full\#supplementary-material

Bird, R. E., Hardman, K. D., Jacobson, J. W., Johnson, S., Kaufman, B. M., Lee, S. M., et al. (1988). Single-chain antigen-binding proteins. Science 242, 423-426. doi: 10.1126/science.3140379

Boonrod, K., Galetzka, D., Nagy, P. D., Conrad, U., and Krczal, G. (2004). Singlechain antibodies against a plant viral RNA-dependent RNA polymerase confer virus resistance. Nat. Biotechnol. 22, 856-862. doi: 10.1038/ nbt983

Bortesi, L., and Fischer, R. (2015). The CRISPR/Cas9 system for plant genome editing and beyond. Biotechnol. Adv. 33, 41-52. doi: 10.1016/j.biotechadv.2014. 12.006

Caussinus, E., Kanca, O., and Affolter, M. (2011). Fluorescent fusion protein knockout mediated by anti-GFP nanobody. Nat. Struct. Mol. Biol. 19, 117-121. doi: $10.1038 / \mathrm{nsmb} .2180$ 
Chowdhury, P. S., and Pastan, I. (1999). Improving antibody affinity by mimicking somatic hypermutation in vitro. Nat. Biotechnol. 17, 568-572. doi: 10.1038/9872

Conrad, U., Fiedler, U., Artsaenko, O., and Phillips, J. (1998). "Single-chain Fv antibodies expressed in plants," in Recombinant Proteins from Plants: Production and Isolation of Clinically Useful Compounds, eds C. Cunningham and A. J. R. Porter (Totowa, NJ: Humana Press), 103-127. doi: 10.1007/978-160327-260-5_9

Conrad, U., and Manteuffel, R. (2001). Immunomodulation of phytohormones and functional proteins in plant cells. Trends Plant Sci. 6, 399-402. doi: 10.1016/ S1360-1385(01)02043-X

Floss, D. M., Mockey, M., Zanello, G., Brosson, D., Diogon, M., Frutos, R., et al. (2010). Expression and immunogenicity of the mycobacterial Ag85B/ESAT-6 antigens produced in transgenic plants by elastin-like peptide fusion strategy. J. Biomed. Biotechnol. 2010:274346. doi: 10.1155/2010/ 274346

Gahrtz, M., and Conrad, U. (2009). Immunomodulation of plant function by in vitro selected single-chain Fv intrabodies. Methods Mol. Biol. 483, 289-312. doi: 10.1007/978-1-59745-407-0_17

Helma, J., Cardoso, M. C., Muyldermans, S., and Leonhardt, H. (2015). Nanobodies and recombinant binders in cell biology. J. Cell Biol. 209, 633-644. doi: 10.1083/ jcb. 201409074

Hensel, G., Floss, D. M., Arcalis, E., Sack, M., Melnik, S., Altmann, F., et al. (2015). Transgenic production of an anti hiv antibody in the barley endosperm. PLOS ONE 10:e0140476. doi: 10.1371/journal.pone.0140476

Himmelbach, A., Zierold, U., Hensel, G., Riechen, J., Douchkov, D., Schweizer, P., et al. (2007). A set of modular binary vectors for transformation of cereals. Plant Physiol. 145, 1192-1200. doi: 10.1104/pp.107.111575

Horsch. (1985). A simple and general method for transferring genes into plants. Science 227, 1229-1231. doi: 10.1126/science.227.4691.1229

Ju Shin, Y., Kyun Park, S., Jung Jung, Y., Na Kim, Y., Sung Kim, K., Kyu Park, O., et al. (2015). Nanobody-targeted E3-ubiquitin ligase complex degrades nuclear proteins. Sci. Rep. 5:14269. doi: 10.1038/srep14269

Lee, D. H., and Goldberg, A. L. (1998). Proteasome inhibitors: valuable new tools for cell biologists. Trends Cell Biology 8, 397-403. doi: 10.1016/S0962-8924(98) 01346-4

Lienert, F., Lohmueller, J. J., Garg, A., and Silver, P. A. (2014). Synthetic biology in mammalian cells: next generation research tools and therapeutics. Nat. Rev. Mol. Cell Biol. 15, 95-107. doi: 10.1038/nrm3738

Miroshnichenko, S., Tripp, J., Nieden, U., Neumann, D., Conrad, U., and Manteuffel, R. (2005). Immunomodulation of function of small heat shock proteins prevents their assembly into heat stress granules and results in cell death at sublethal temperatures. Plant J. 41, 269-281. doi: 10.1111/j.1365-313X. 2004.02290.x

Muyldermans, S. (2013). Nanobodies: natural single-domain antibodies. Annu. Rev. Biochem. 82, 775-797. doi: 10.1146/annurev-biochem-063011092449

Nishimura, K., Fukagawa, T., Takisawa, H., Kakimoto, T., and Kanemaki, M. (2009). An auxin-based degron system for the rapid depletion of proteins in nonplant cells. Nat. Methods 6, 917-922. doi: 10.1038/nmeth.1401
Ravid, T., and Hochstrasser, M. (2008). Diversity of degradation signals in the ubiquitin-proteasome system. Nat. Rev. Mol. Cell Biol. 9, 679-690. doi: 10.1038/ nrm 2468

Sakamoto, K. M., Kim, K. B., Kumagai, A., Mercurio, F., Crews, C. M., and Deshaies, R. J. (2001). Protacs: chimeric molecules that target proteins to the Skp1-Cullin-F box complex for ubiquitination and degradation. Proc. Natl. Acad. Sci. U.S.A. 98, 8554-8559. doi: 10.1073/pnas.141230798

Sambrook, J. (2001). in Molecular Cloning: A Laboratory Manual, eds J. Sambrook and D. W. Russell (Cold Spring Harbor, NY: Cold Spring Harbor Laboratory).

Staniek, A., Bouwmeester, H., Fraser, P. D., Kayser, O., Martens, S., Tissier, A., et al. (2013). Natural products - modifying metabolite pathways in plants. Biotechnol. J. 8, 1159-1171. doi: 10.1002/biot.201300224

Tavladoraki, P., Benvenuto, E., Trinca, S., De Martinis, D., Cattaneo, A., and Galeffi, P. (1993). Transgenic plants expressing a functional single-chain Fv antibody are specifically protected from virus attack. Nature 366, 469-472. doi: $10.1038 / 366469 \mathrm{a} 0$

ten Hoopen, P., Hunger, A., Müller, A., Hause, B., Kramell, R., Wasternack, C., et al. (2007). Immunomodulation of jasmonate to manipulate the wound response. J. Exp. Bot. 58, 2525-2535. doi: 10.1093/jxb/erm 122

Vierstra, R. D. (2009). The ubiquitin-26S proteasome system at the nexus of plant biology. Nat. Rev. Mol. Cell Biol. 10, 385-397. doi: 10.1038/nrm2688

Visintin, M., Meli, G. A., Cannistraci, I., and Cattaneo, A. (2004). Intracellular antibodies for proteomics. J. Immunol. Methods 290, 135-153. doi: 10.1016/j. jim.2004.04.014

Volkov, R. A., Panchuk, I. I., and Schoffl, F. (2003). Heat-stress-dependency and developmental modulation of gene expression: the potential of house-keeping genes as internal standards in mRNA expression profiling using real-time RT-PCR. J. Exp. Bot. 54, 2343-2349. doi: 10.1093/jxb/erg244

Zhao, D., Ni, W., Feng, B., Han, T., Petrasek, M. G., and Ma, H. (2003). Members of the Arabidopsis-SKP1-like gene family exhibit a variety of expression patterns and may play diverse roles in Arabidopsis. Plant Physiol. 133, 203-217. doi: $10.1104 /$ pp.103.024703

Zhou, P. (2005). Targeted protein degradation. Curr. Opin. Chem. Biol. 9, 51-55. doi: 10.1016/j.cbpa.2004.10.012

Zhou, P., Bogacki, R., McReynolds, L., and Howley, P. M. (2000). Harnessing the ubiquitination machinery to target the degradation of specific cellular proteins. Mol. Cell 6, 751-756. doi: 10.1016/S1097-2765(00)00074-5

Conflict of Interest Statement: The authors declare that the research was conducted in the absence of any commercial or financial relationships that could be construed as a potential conflict of interest.

Copyright (C) 2018 Baudisch, Pfort, Sorge and Conrad. This is an open-access article distributed under the terms of the Creative Commons Attribution License (CC BY). The use, distribution or reproduction in other forums is permitted, provided the original author(s) and the copyright owner are credited and that the original publication in this journal is cited, in accordance with accepted academic practice. No use, distribution or reproduction is permitted which does not comply with these terms. 